\title{
Neurological soft signs as an endophenotype in an African schizophrenia population - a pilot study
}

\author{
I Smit', L Koen', DJH Niehaus', E Jordaan², UA Botha' \\ 1Department of Psychiatry, University of Stellenbosch and Stikland Hospital, Stellenbosch, South Africa \\ 2Medical Research Council of South Africa, Bellville, South Africa
}

\begin{abstract}
Objective: The use of endophenotypes, such as neurological soft signs (NSS), is advocated as one possible method to elucidate the heterogeneity of schizophrenia. Exploring the associations between NSS and specific illness symptoms has revealed some trends, although results have been conflicting. To date, such studies have been conducted largely on Caucasian populations and our pilot study represents the first attempt to gather such data in a homogenous African population. Method: Fifty-one patients, all of Xhosa ethnicity and participating in a larger schizophrenia genetic study were recruited. NSS were evaluated using a modified Neurological Evaluation Scale. Data were analysed using SPSS with the strength of the overall relationships between NES groups and SANS and SAPS components analyzed by means of canonical correlation analysis. Results: The canonical correlation of SANS domains (excluding asociality) with the NES conceptual groups was 0.53 (SE=0.1 1, p=0.024) and of the SAPS domains 0.38 ( $\mathrm{SE}=0.13, \mathrm{p}=0.943$ ). Conclusion: Our results suggest a correlation between negative symptoms of schizophrenia and the presence of NSS, supporting the recruitment of a larger sample to more comprehensively evaluate a possible role for NSS as an endophenotype in the Xhosa schizophrenia population. Taking into account that NSS evaluations allow for inexpensive, relatively easy-to-do objective evaluations, this method presents us with a valuable research tool that can be used effectively within our under-resourced environment to help inform on the neurobiological substrate of schizophrenia.
\end{abstract}

Keywords: Schizophrenia; Endophenotype; Neurological Soft Signs

Received: 03-06-2011

Accepted: 06-06-201 1

doi: http://dx.doi.org/10.4314/ajpsy.v15i2.17

\section{Introduction}

Schizophrenia is a severe chronic psychiatric disorder that shows considerable clinical heterogeneity which arguably reflects the heterogeneous nature of susceptibility factors for the illness. ${ }^{1}$ Currently there is uncertainty as to whether this is a single disorder with different clinical manifestations or in fact a group of syndromes, each with unique or overlapping pathophysiology.

Considerable attempts have been made to elucidate the heterogeneity of the schizophrenia phenotype by exploring

Correspondence:
Dr I Smit
Department of Psychiatry
PO Box 19063, Faculty of Health Sciences, University of Stellenbosch,
Tygerberg, 7505, South Africa
email: ingemarligmail.com

the relationships between the various symptom dimensions and possible subtypes. One possible method would be to consider a role for endophenotypes. Several approaches have been advocated for endophenotype analysis in schizophrenia, such as demographic and clinical variables, physical characteristics and neurodevelopmental insults. ${ }^{2}$

The neurodevelopmental hypothesis of schizophrenia holds that the etiological origins of the disease can be traced back to disturbed early prenatal development. ${ }^{3-5}$ Currently, numerous diverse lines of evidence support this hypothesis, including the presence of obstetric complications, epidemiological data (i.e. in utero disease and stress exposure), the presence of pre-morbid behavioral and neuromotor deficits, the observed pattern of developmental brain anomalies, the increased rate of dysmorphic features and a higher frequency of neurological soft signs. ${ }^{6-12}$

Neurological "subtle" or "soft" signs (NSS) are 
abnormalities that illustrate generalised and non-specific neurological pathology and a large body of literature exists that consistently supports an excess of NSS in schizophrenia patients. ${ }^{13}$ These seem to mainly be localized to the three neurological domains conceptualized (based on neuroanatomy and function) by Buchanan and Heinrich.s. ${ }^{14}$ These are integrative sensory function (deficits possibly resulting from a dysfunction of the heteromodal cortex), motor coordination (deficits possibly related to basal ganglia abnormalities) and sequencing of complex motor tasks (deficits possibly resulting from a dysfunction of the frontobasal ganglial circuitry). ${ }^{15,16}$

Several authors have attempted to search for an association between NSS and specific symptoms of schizophrenia. ${ }^{17,18}$ Results have often been conflicting although trends for relationships with specifically negative symptoms and disorganization seem to have emerged. ${ }^{19-25}$

To date, NSS schizophrenia symptom correlation studies have been conducted largely on Caucasian populations and as such this pilot study represents the first attempt to gather such data in a homogenous African population.

\section{Method \\ Subjects}

Over a period of 24 months, a group of potential participants, all of Xhosa (African population of the Nguni language group) ethnicity and known to have a diagnosis of schizophrenia, were recruited from in- and outpatient hospital services and community clinics in the Western Cape Province of South Africa for participation in an international genetic study. ${ }^{26}$ The larger study methodology is fully documented in previous publications from our group. ${ }^{27}$ In conjunction with the abovementioned a number of sub-projects were also initiated concurrently, using convenience samples from the larger study population. All of the subjects who presented for assessment for one such study were approached in consecutive order by a Xhosa-speaking social scientist to discuss possible participation in this study. Of the 51 patients approached, all agreed to participate. Once again subjects were screened as according to the inclusion and exclusion criteria and informed consent was obtained prior to any study procedures being initiated.

\section{Assessments}

A diagnosis of schizophrenia was confirmed using the Diagnostic Interview for Genetic Studies (2.0), (DIGS). ${ }^{28}$ The interview was conducted in English and/or Xhosa, and supporting information was obtained from collateral sources. The DIGS is a comprehensive clinical assessment interview specially developed for diagnosing major mood and psychotic spectrum disorders and also includes the Schedules for the Assessment of Positive and Negative Symptoms (SAPS, SANS). ${ }^{29,30}$ The SANS and SAPS each assess symptom complexes to obtain clinical ratings of negative and positive symptoms respectively in patients with schizophrenia and domain scores were derived by summing the items.

One clinician evaluated NSS in the study population using a modified Neurological Evaluation Scale (NES). ${ }^{14}$ The modified NES was based on those items previously selected by Emsley et al in a South African population and Keshevan et al whose modifications consisted of discarding those items that were abnormal in less than $10 \%$ of their samples. ${ }^{16,31}$

\section{Data analysis}

Data were analysed using SPSS software (version 13.0). For analysis items were divided according to a conceptual framework for neurological "soft signs", putting items into 4 groups namely sensory integration (sensory), motor coordination (motor), sequencing of complex motor acts (sequencing) and others. ${ }^{14}$ (Table I). The strength of the overall relationships between the four groups and SANS components (affective changes, alogia, avolition/apathy and asociality) and SAPS components (hallucinations, delusions, thought disorder, behavioural changes) were analyzed by means of canonical correlation analysis as this method allowed us to simultaneously predict multiple dependent variables from multiple independent variables. ${ }^{32}$

\section{Ethical Considerations}

The study was approved by the Committee for Human Research, Faculty of Health Sciences, University of Stellenbosch (97/005) and all their regulations were strictly adhered to.

\begin{tabular}{|c|c|c|c|}
\hline Sensory integration & Motor co-ordination & Sequencing of complex motor acts & Other \\
\hline $\begin{array}{l}\text { Audio-visual integration } \\
\text { Graphaesthesia } \\
\text { Extinction } \\
\text { Right-left confusion } \\
\text { Stereognosis }\end{array}$ & $\begin{array}{l}\text { Tandem walk } \\
\text { Rapid alternating movements } \\
\text { Finger-thumb opposition } \\
\text { Finger-to-nose test }\end{array}$ & $\begin{array}{l}\text { First-ring test } \\
\text { Fist-edge-palm test } \\
\text { Ozeretski test } \\
\text { Rhythm tapping test B }\end{array}$ & $\begin{array}{l}\text { Romberg sign } \\
\text { Memory } \\
\text { Rhythm tapping test A } \\
\text { Mirror movements } \\
\text { Synkinesis } \\
\text { Convergence } \\
\text { Gaze impersistence } \\
\text { Glabellar reflex } \\
\text { Snout reflex } \\
\text { Grasp reflex } \\
\text { Suck reflex } \\
\text { Tremor } \\
\text { Adventitious overflow }\end{array}$ \\
\hline
\end{tabular}




\section{Results}

The sample comprised 51 subjects ( 15 female, 36 male) with a mean age on interview of 38.24 years (SD 1 1.44). Mean age of onset of illness was 24.59 years (SD 7.75), with mean duration of illness 13.64 years (SD 9.31)

Table II summarizes the mean scores for each NES grouping as well as the SANS and SAPS scores and subscores.

The canonical correlation of SANS domains (excluding asociality) with the NES conceptual groups is 0.53 (SE=0.11, $\mathrm{p}=0.024)$. The first canonical variable (Vl) for NES conceptual groups is a weighted difference of motor, sequencing, others and sensory, while the first canonical variable (Wl) for the SANS domains is a weighted average of alogia, avolition and affective changes (see Table III).

The canonical correlation of the SAPS domains with the NES

Table II: Mean scores for each NES grouping as well as the SANS and SAPS scores and subscores

\begin{tabular}{|l|l|l|}
\hline & Mean & Std. Deviation \\
\hline Sensory Integration & 2.6735 & 2.12513 \\
Motor Co-ordination & .1961 & .52989 \\
Sequencing & 1.8431 & 2.28362 \\
Others & 1.8627 & 1.70903 \\
Total NES & 6.4490 & 5.53798 \\
Duration illness (years) & 13.6471 & 9.31842 \\
SANS Total & 13.0800 & 7.15952 \\
SANS Alogia & 6.2353 & 4.32476 \\
SANS Avolition & 8.2353 & 4.36160 \\
SANS Asociality & 9.6667 & 2.88675 \\
SAPS Total & 14.91 & 17.69 \\
SAPS Hallucinations & 4.5918 & 6.29126 \\
SAPS Delusions & 4.9574 & 6.98743 \\
SAPS Behaviour & 1.5000 & 3.24037 \\
SAPS Thought & 3.7200 & 5.02662 \\
\hline
\end{tabular}

Table III: Standardized Canonical Coefficients for the NES and SANS Variables

\begin{tabular}{|l|l|l|}
\hline & V1 & W1 \\
\hline Sensory Integration & -0.6544 & - \\
Motor Co-ordination & 0.4471 & - \\
Sequencing & 0.1898 & - \\
Others & 0.9846 & - \\
Alogia & - & 0.3511 \\
Avolition/apathy & - & 0.4772 \\
Affective changes & - & 0.3486 \\
\hline
\end{tabular}

Table IV: Standardized Canonical Coefficients for the NES and SAPS Variables

\begin{tabular}{|l|l|l|}
\hline & V1 & W1 \\
\hline Sensory Integration & -1.3653 & - \\
Motor Co-ordination & 0.3542 & - \\
Sequencing & -0.2861 & - \\
Others & 0.9078 & - \\
Hallucinations & - & -0.2136 \\
Delusions & - & 0.6878 \\
Behavioural changes & - & 0.6644 \\
Thought disorder & - & -0.2721 \\
\hline
\end{tabular}

groups is 0.38 ( $\mathrm{SE}=0.13, \mathrm{p}=0.943)$. The first canonical variable (Vl) for NES is as described above, while the first canonical variable (Wl) for SAPS domains is a weighted average of the four variables hallucinations, delusions, behavioural changes and thought disorder (see Table IV).

Significant correlations between the NES groups and SANS components, but not the SAPS components could thus be demonstrated.

\section{Discussion}

Our results suggest a correlation between negative symptoms of schizophrenia and the presence of neurological soft signs in our study population. A number of studies have found a positive relationship between NSS and clinical correlates in schizophrenia. ${ }^{17,33}$

Whilst reported results have at times been conflicting, the association between NSS and negative symptoms seems particularly robust. ${ }^{13,19-25}$ However, this association has not been confirmed by all studies. ${ }^{34-36}$ Rather the link seems to be more clear in samples with a severe or chronic illness outcome eg persistence of negative symptoms in spite of adequate antipsychotic treatment. ${ }^{37,38}$ Our sample seems to fit this mould, taken into account the mean duration of illness and presence of ongoing positive and negative symptoms as evidenced by the SANS and SAPS. In their review Tosato and Dazzan commented that the association between an excess of NSSs and a negative syndrome seemed appropriate as it could well be explained by the hypothesis that negative symptoms are the behavioural correlates of an underlying central nervous system disorder possibly involving a dysfunction in the cerebellum and affecting the integrity of the frontal lobe. ${ }^{33}$

As previously noted a paucity of data exist regarding associations between clinical correlates and NSS in nonCaucasian populations. In fact, very few studies have investigated a possible effect for ethnicity on NSS. Available data suggest increased NSS in African patients in comparison to Caucasians, in contrast to Asian patients where no significant differences were found. ${ }^{14,38,39}$

In their comprehensive review of NSS as a possible endophenotype in schizophrenia Liu et al conclude that in spite of the many challenges it is much too early to disregard the usefulness of the role NSS could play. ${ }^{17}$ Our pilot study's findings support this and the recruitment of a larger sample to more comprehensively evaluate a possible role for NSS as an endophenotype in the homogenous Xhosa schizophrenia population seems warranted.

\section{Conclusion}

Taking into account that NSS evaluations allow for inexpensive, relatively easy-to-do objective evaluations, this method presents us with a valuable research tool that can be used effectively within our under-resourced environment to help inform on the neurobiological substrate of the schizophrenia. The suggested excess of NSS in homogenous African populations provides further support for its use as a marker for study in this group.

\section{References}

1. Gottesman II, Shields J. Genetic theorizing and schizophrenia. British Journal of Psychiatry 1973; 122: 15-30.

2. Gottesman II, Gould TD. The endophenotype concept in psychiatry: 
Etymology and strategic intentions. American Journal of Psychiatry 2003; 160: 636-645.

3. Marenco S, Weinberger DR. The neurodevelopmental hypothesis of schizophrenia: Following a trail of evidence from cradle to grave. Developmental Psychopathology 2000; 12: 501-527.

4. McGrath JJ, Feron FP, Burne TH, et al. The neurodevelopmental hypothesis of schizophrenia: A review of recent developments. Annals of Medicine 2003; 35: 86-93.

5. Weinberg SM, Jenkins EA, Marazita ML, et al. Minor physical anomalies in schizophrenia: A meta-analysis. Schizophrenia Research 2007; 89: 72-85.

6. Cannon $M$, Dean $K$, Jones P. Early environmental risk factors for schizophrenia. In: Keshavan, M, Kennedy, J, Murray, R, eds. Neurodevelopment and Schizophrenia. Cambridge: Cambridge University Press 2004; 191-209.

7. Cannon M, Jones PB, Murray RM. Obstetric complications and schizophrenia: Historical and meta-analytic review. American Journal of Psychiatry 2002; 159: 1080-1092.

8. Harrison PJ. The neuropathology of schizophrenia: A critical review of the data and their interpretation. Brain 1999; 122: 593-624.

9. Kravariti E, Dazzan P, Fearon P, et al. Can one identify preschizophrenic children? In: Keshavan, MS, Kennedy, JL, Murray, RM, eds. Neurodevelopment and Schizophrenia. Cambridge: Cambridge University Press 2004; 415-431.

10. McNeil TF, Cantor-Graae E, Ismail B. Obstetric complications and congenital malformation in schizophrenia. Brain Research Review 2000; 31: 166-178.

11. Murphy KC, Owen MJ. Minor physical anomalies and their relationship to the aetiology of schizophrenia. British Journal of Psychiatry 1996; 168: 139-142.

12. Weinberger DR. Implications of normal brain development for the pathogenesis of schizophrenia. Archives of General Psychiatry 1987; 44: 660-669.

13. Compton MT, Bollini AM, McKenzi Mack L, et al. Neurological soft signs and minor physical anomalies in patients with schizophrenia and related disorders, their first-degree biological relatives, and nonpsychiatric controls. Schizophrenia Research 2007; 94: 64-73.

14. Buchanan RW, Heinrichs DW. The Neurological Evaluation Scale (NES): A structured instrument for the assessment of neurological signs in schizophrenia. Psychiatry Research 1989; 27: 335-350.

15. Dazzan P, Morgan KD, Orr KG, et al. The structural brain correlates of neurological soft signs in AESOP first-episodes psychosis study. Brain 2004; 127: 143-153.

16. Keshavan MS, Sanders RD, Sweeney JA, et al. Diagnostic specificity and neuroanatomical validity of neurological abnormalities in firstepisode psychoses. American Journal of Psychiatry 2003; 160: 1298-1304

17. Hui CLM, Wong GHY, Chiu CPY, et al. Potential Endophenotype for Schizophrenia: Neurological Soft Signs. Annals Acadamy of Medicine Singapore 2009; 38:408-413.

18. Dazzan P, Murray RM. Neurological soft signs in first-episode psychosis: a systematic review. British Journal of Psychiatry Suppl 2002; 43:S50-s57.

19. Whitty P, Clarke M, McTigue O, et al. Diagnostic specificity and predictors of neurological soft signs in schizophrenia, bipolar disorder and other psychoses over the first 4 years of illness Schizophrenia Research 2006; 86(1-3): 110-117. Electronic publication 2006 Jun 9

20. Biswas P, Malhotra S, Malhotra A, et al. Comparative study of neurological soft signs in schizophrenia with onset in childhood, adolescents and adulthood. Acta Psychiatrica Scandinavica 2007;
115: 295-303

21. Jahn T, Hubmann W, Karr M, et al. Motoric neurological soft signs and psychopathological symptoms in schizophrenic psychoses. Psychiatry Research 2006; 142(2-3): 191-9. Electronic publication 2006 May 2.

22. Merriam AE, Kay SR, Opler LA, et al. Neurological signs and the positive-negative dimension in schizophrenia. Biological Psychiatry 1990; 28: 181-92.

23. Mohr F, Hubmann W, Cohen R, et al. Neurological soft signs in schizophrenia: Assessment and correlates. European Archives of Psychiatry and Clinical Neuroscience 1996; 246(5): 240-8.

24. Scheffer RE. Abnormal neurological signs at the onset of psychosis. Schizophrenia Research 2004; 70: 19-26.

25. Ruiz-Veguilla M, Cervilla JA, Barringón ML, et al. Neurodevelopmental markers in different psychopathological dimensions of first episode psychoses: The ESPIGAS study. European Journal of Psychiatry 2008; 23(8): 533-40, Electronic publication 2008; Jun 27.

26. American Psychiatric Association. The diagnostic and statistical Manual of Mental Disorders, Fourth edition, Text revision, (DSM-IVTR). Washington DC: American Psychiatric Press; 2000.

27. Niehaus DJ, Koen L, Laurent C, et al. Positive and negative symptoms in affected sib pairs with schizophrenia: Implications for genetic studies in an African Xhosa sample. Schizophrenia Research 2005; 79. 239-249.

28. Nurnberger JI Jr., Blehar MC, Kaufmann CA, et al. Diagnostic interview for genetic studies: Rationale, unique features, and training. NIMH Genetics Initiative, Archives of General Psychiatry 1994; 51 : 849-859.

29. Andreasen NC. The Scale for the Assessment of Negative Symptoms (SANS): Conceptual and theoretical foundations. British Journal of Psychiatry 1989; Suppl, 49-58.

30. Andreasen NC, Arndt, S, Miller, et al. Correlational studies of the Scale for the Assessment of Negative Symptoms and the Scale for the Assessment of Positive Symptoms: An overview and update. Psychopathology 1995; 28: 7-17.

31. Emsley R, Turner HJ, Oosthuizen PP, et al. Neurological abnormalities in first-episode schizophrenia: Temporal stability and clinical outcome correlates. Schizophrenia Research 2005; 75(1): 35-44.

32. Mardia KV, Kent JT, and Bibby JM. Multivariate Analysis London; New York : Academic Press, 1979.

33. Tosato S, Dazzan P. The psychopathology of schizophrenia and the presence of neurological soft signs: A review. Current Opinion in Psychiatry 2005; 18(3): 285-288.

34. Ohaeri JU, Otote DI. Subtypes and factors of schizophrenia in an acutely ill Nigerian sample. Psychopathology 2003; 36: 181-189.

35. Mohr F, Hubmann W, Albus M, et al. Neurological soft signs and neuropsychological performance in patients with first episode schizophrenia. Psychiatry Research 2003; 121 (1): 21-30.

36. Shibre T, Kebede D, Alema A, et al. Neurological soft signs (NSS) in 200 treatment-naive cases with schizophrenia: A community-based study in a rural setting. Nordic Journal of Psychiatry 2002; 56(6): 425-31.

37. Das M, Kumari V, Soni W, et al. Neurological soft signs and their relationship to cognitive and clinical efficacy of atypical antipsychotics in schizophrenia. Schizophrenia Bulletin 2004; 30(2): 241-53.

38. Chen EYH, Chan RCK. The Cambridge Neurological Inventory: Clinical, demographic, and ethnic correlates. Psychiatric Annals 2003; 33: 202-10.

39. Gureje O. Neurological soft signs in Nigerian schizophrenics: A controlled study. Acta Psychiatrica Scandinavica 1988; 78: 505-9. 